\title{
CD161a to Lymphocyte Ratio Measurement
}

National Cancer Institute

\section{Source}

National Cancer Institute. CD161a to Lymphocyte Ratio Measurement. NCI Thesaurus. Code C122104.

The determination of the ratio of CD161a expressing cells to total lymphocytes present in a sample. The measurement by be expressed as a ratio or percentage. 